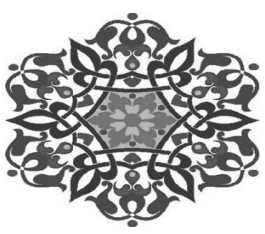

\title{
Teologi Ahmadiyah
}

\author{
Abd. Muid N. \\ UIN Syarif Hidayatullah Jakarta DPK Institut PTIQ Jakarta \\ e-mail:muid_bugis@yahoo.com \\ HP 08561177495
}

\begin{abstract}
Abstraks: Tidak bisa dipungkiri kebesaran Ahmadiyah karena pengikutnya yang banyak bahkan membuatnya dianggap oleh sebagian Islamolog sebagai bagian dari warna Islam selain Sunni dan Syiah. Tulisan ini tidak akan menelusuri kembali absah tidaknya Ahmadiyah tetapi lebih kepada memahami bagaimana Ahmadiyah dengan melihat pada latar belakang seperti apa yang membuat Ahmadiyah bisa timbul ke permukaan lalu menyebar ke seluruh penjuru dunia lewat sudut pandang sosio-teologis. Untuk itu, tulisan ini mengetengahkan Ahmadiyah dalam konsep-konsep seperti Messianisme, Mahdiisme, dan aliran pembaruan. Penyebaran Ahmadiyah ditentukan oleh momentum yang tepat dan aktivisme yang kuat oleh para pengikutnya.
\end{abstract}

Kata kunci: messianisme, mahdiisme, tajdîd,

\section{A. Pendahuluan}

Kontroversi Ahmadiyah tidak akan pernah berakhir karena penganut Ahmadiyah juga masih sangat banyak dan tersebar di seluruh dunia bahkan mempunyai andil besar bagi penyebaran Islam di Barat, Arfrika, dan Asia. Di Indonesia, Ahmadiyah tidak kurang kontroversialnya. Banyak yang mendorong agar negara turun tangan untuk mengeluarkan Ahmadiyah dari Islam secara resmi, namun banyak pula yang menganggap Ahmadiyah sebagai minoritas yang harus dibela haknya untuk beragama menurut keyakinannya. Tidak jarang terjadi pengrusakan tempat ibadah yang dipakai oleh pengikut Ahmadiyah. Namun isu Ahmadiyah timbul tenggelam di Indonesia jika ada isu lain yang dianggap le- 
bih menarik. Tulisan ini membahas bagaimana secara sosio-teologis Ahmadiyah bisa dipahami.

\section{B. Sekilas Sejarah}

Mirza Ghulam Ahmad (1835-1908), adalah pendiri gerakan Ahmadiyah, lahir di Qadian, sebuah desa di Punjab. Pada awal 1880-an, Ghulam Ahmad mendeklarasikan bahwa dirinya mempunyai kedudukan spiritual khusus. Lalu berdirilah gerakan Ahamdiyah ketika Ghulam Ahmad menerima sumpah setia dari sejumlah pengikutnya di Ludhiana, Punjab.

Ketika Ghulam Ahmad meninggal pada pada 26 Mei 1908, kepemimpinannya digantikan oleh Nuruddin, salah seorang pengikut awalnya, bergelar Khalîfah al-Masîh I. Lalu Nuruddin digantikan oleh putra Ghulam Ahmad, Basyiruddin Mahmud Ahmad (Khalîfah al-Masîh II). Pada masa kepemimpinan Basyiruddin lah kontroversi Ahmadiyah memuncak. Salah satu yang diduga menjadi penyebabnya adalah lokasi Ahmadiyah yang berpusat di Pakistan dan Pakistan adalah sebuah republik Islam.

Sejak berdirinya, Ahmadiyah punya dedikasi tinggi dalam menyebarkan Islam secara umum dan Islam versinya lewat publikasi tulisan, organisasi, pengembangan komunitas, hingga berhadapan dengan ulama Sunni, misionaris Kristen, dan pembaru Hindu. Untuk urusan penyebaran Islam, Ahmadiyah punya jasa yang sangat besar. Dedikasi Ahmadiyah ini mungkin berkaitan dengan pemahaman Ghulam Ahmad tentang jihâd. Menurutnya, jihâd di masa Ghulam Ahmad tidak lagi bisa diartikan perjuangan militer karena Islam tidak lagi ada ancaman militer serius terhadap Islam. Jihâd lebih bermakna perlawanan terhadap gerakan missionaris Kristen. ${ }^{1}$ Oleh para penentangnya, pemaknaan jihâd oleh Ghulam Ahmad seperti itu dianggap sebagai pemahaman titipan penjajah Inggris yang bermaksud melemahkan semangat juang Muslim terhadap penjajah. Namun dalam hal jihâd Ahmadiyah terhadap missionaris Kristen, kita mungkin menjadi paham mengapa dan dalam kondisi sosial keagamaan seperti apa ceramah model Zakir Naik menjadi sangat populer India dan Pakistan hingga ke Indonesia. Di sana memang ada kondisi persaingan perebutan pengikut lewat adu argument teologis.

\section{Ahmadiyah, Agama, dan Politik}

Kontroversi Ahmadiyah tidak bisa dilepaskan dari politik meski argumen penolakannya oleh ulama berdasar pada persoalan teologi Islam, yaitu

${ }^{1}$ Yohanan Friedmann, "Ahmadiyya", dalam Encyclopaedia of Qur'an Volume 1, Jane Dammen McAuliffe (ed.), (Leiden: Brill, 2001), hal. 51. 
klaim kenabian. Klaim Ahmadiyah tentang keberlanjutan kenabian setelah Nabi Muhammad saw adalah kontroversi paling melegenda di masa Islam modern. Dan itu memuncak pada kepemimpinan Basyiruddin Mahmud Ahmad, putra Ghulam Ahmad. Lalu Ahmadiyah pun terbelah. Faksi Qadiyani menekankan klaim kenabian Ghulam Ahmad, kekuasaan tak terbatas penerusnya, Basyiruddin Mahmud Ahmad, dan menganggap kafir Muslim non-Ahmadiyah. Faksi Lahori berpendapat bahwa Ghulam Ahmad tidak pernah mengklaim lebih daripada seorang "pembaru" (mujaddid) agama, kekuasaan tidak pada penerus Ghulam Ahmad tetapi pada Majelis Tertinggi Ahmadiyah, dan hanya menganggap kafir orang yang mengkafirkan mereka. Masih perlu kajian lebih jauh mengapa faksi Lahori memilih klaim mujaddid bagi Ghulam Ahmad. Apakah memang seperti itu atau lebih merupakan upaya untuk menjinakkan kontroversi yang memang hampir tak terbendung.

Kelompok minoritas dan perempuan memang mempunyai persoalannya sendiri dalam Islam. Persoalan yang menghinggapi Ahmadiyah adalah persoalan kelompok minoritas. Dan satiap agama atau aliran yang terorganisir kemungkinan besar menghadapi masalah serupa. Di sekitar tahun 1953, di Pakistan, terjadi kerusuhan-kerusuhan ketika Jamaat-i-Islami dan para ulama mendorong agar kelompok Islam Ahmadiyah atau Qadiyani, dinyatakan sebagai kelompok non-Muslim. Jadilah pada tahun 1974, setelah awalnya menentang, pemerintahan Zulfikar Ali Bhutto dan Dewan Nasional mengamandemen Konstitusi untuk secara resmi menyatakan bahwa Qadiyani adalah minoritas non-Muslim. Pada tahun 1984, di bawah pemerintahan Presiden Zia ul-Haq, dikeluarkan resolusi, yang (1) menyerukan pemerintah agar menegakkan sanksi menurut hukum Islam (hukuman mati) karena murtad dan (2) menuntut agar Qadiyani dilarang menggunakan istilah-istilah Islam dan para anggotanya harus dipecat dari jabatan sipil dan militer. ${ }^{2}$

Tampak dari resolusi di atas bahwa Ahmadiyah memang hendak diberangus sampai akar-akarnya. Hukuman mati bagi yang murtad atau yang meninggalkan Islam ortodoks untuk menjadi Ahmadiyah sama saja memaksa pengikut Ahmadiyah untuk meninggalkan Ahmadiyah. Sedangkan melarang pengikut Ahmadiyah untuk menduduki jabatan sipil dan militer merupakan upaya menutup akses pengikut Ahmadiyah di ruang publik. Inilah yang disebut kontroversi Ahmadiyah tidak bisa dilepaskan dari politik. Keyakinan yang awal-

${ }^{2}$ Pada waktu itu, seorang Ahmadiyah terkemuka bernama Muhammad Zafarullah Khan menduduki jabatan Menteri Luar Negeri Pakistan. Yohanan Friedmann, "Ahmadiyah", dalam Ensiklopedi-Oxford Dunia Islam Modern Jilid 1, John L. Esposito (ed.), (Bandung: Mizan, 2002), hal. 81. John L. Esposito, Islam Warna-Warni: Ragam Ekspresi Menuju “Jalan Lurus”, (Jakarta: Paramadina, 2004), hal. 247-248. 
nya adalah relasi manusia dengan Tuhannya lalu berdampak kepada kehidupan sosial, ekonomi dan politiknya.

\section{Ahmadiyah dan Al-Quran}

Ahmadiyah adalah salah satu aliran yang teguh meyakini ketidakterkalahan al-Quran. Bagi mereka, keunikan dan validitasnya tidak perlu dipertanyakan lagi. Ahmadiyah menggalakkan penerjemahan al-Quran ke dalam berbagai bahasa dengan keyakinan bahwa al-Quran lah satu-satunya kitab suci yang keasliannya masih terjaga baik. ${ }^{3}$ Karena itu, anggapan bahwa ada kitab suci lain bagi Ahmadiyah selain al-Quran perlu mendapatkan penjelasan dari sudut pandang lain karena menurut mereka, Tadzkirah (yang dianggap kitab suci Ahmadiyah) adalah tidak lebih dari:

"catatan harian Mirza Ghulam Ahmad yang berisi himpunan wahyu, ilham-ilham, kasyaf-kasyaf, mimpi-mimpi, dan rukya-rukya yang diterima Mirza Ghulam Ahmad dari Allah swt yang dikumpulkan dari berbagai buku, karangan, tulisan-tulisan dan selebaran-selebaran yang pernah beliau tulis di masa hayatnya, yang secara serial dan bertahap disusun oleh Maulana Muhammad Ismail, H. A., Syekh Abdul Qadir, Shd, dan Maulana Abdul Rasyid."4

Meski demikian, Ahmadiyah cenderung melakukan penafsiran modern terhadap ayat-ayat yang tampak tidak masuk akal. Seorang aktivis Ahmadiyah, Ahmad Muhammad Djojosugito dari Yogya, pada tahun 1950-an, menulis di majalah Media, dengan nama samaran, pemikirannya bahwa Nabi Isa as adalah manusia biasa yang lahir dari seorang ibu bernama Maryam, yang telah menikah dengan seorang lelaki bernama Yusuf, tukang kayu. ${ }^{5}$

Pandangan Ahmadiyah tentang konsep naskh agak berbeda. Bagi Ahmadiyah, naskh yang disebutkan di dalam al-Quran bermakna naskh terhadap seluruh agama lain, bukan naskh satu ayat terhadap ayat lain. Menurut Ahmadiyah, di dalam al-Quran tidak ada naskh ayat terhadap ayat lain dan. Karena itu, al-Quran adalah kitab yang solid. Kenyataan bahwa memang di dalam al-Quran ada yang bertentangan, mereka hadapi dengan mengakui kesetaraan semua ayatnya lalu menyesuaikan pengamalan umat pada kondisi yang sesuai dengan

${ }^{3}$ ahmadiyah.id (diakses pada 20 Juli 2017)

${ }^{4}$ Yohanan Friedmann, "Ahmadiyya", dalam Encyclopaedia of Qur'an Volume 1, Jane Dammen McAuliffe (ed.), hal. 51.

${ }^{5}$ M. Dawam Rahardjo, "Mitos dalam Agama dan Kebudayaan", dalam Rekonstruksi dan Renungan Religius Islam, Muhamad Wahyuni Nafis (ed.), (Jakarta: Paramadina, 1996), hal. 206. Dalam tulisannya, M. Dawam Rahardjo memilih kata "aktivis" bagi pengikut Ahmadiyah, mungkin karena menganggap Ahmadiyah lebih merupakan organisasi keagamaan. 
dirinya. Dalam teologi Ahmadiyah, ada ayat yang sangat populer yaitu QS. Ali Imran/3:55:

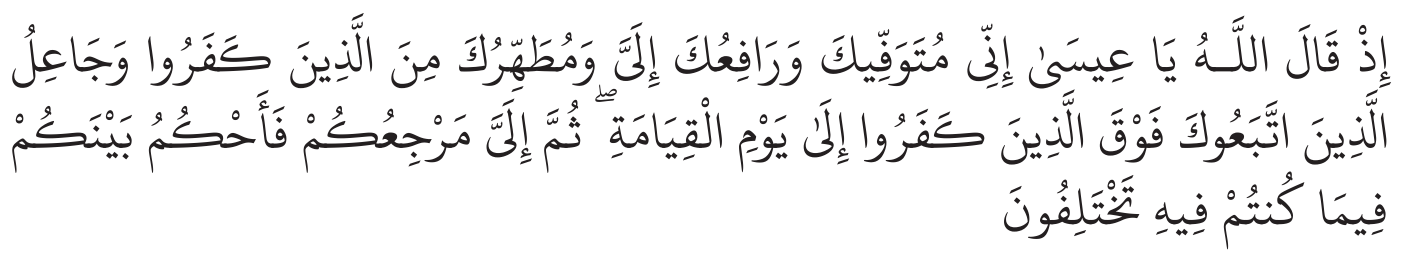

(ingatlah), ketika Allah berfirman: "Hai Isa, Sesungguhnya aku akan menyampaikan kamu kepada akhir ajalmu dan mengangkat kamu kepada-Ku serta membersihkan kamu dari orang-orang yang kafir, dan menjadikan orang-orang yang mengikuti kamu di atas orang-orang yang kafir hingga hari kiamat. kemudian hanya kepada Akulah kembalimu, lalu aku memutuskan di antaramu tentang hal-hal yang selalu kamu berselisih padanya".

Menurut Ahmadiyah, ayat di atas menegaskan kenaikan Nabi Isa as terjadi setelah wafatnya. Ayat itu sekaligus penolakan atas penyaliban Nabi Isa as (QS. al-Nisa [4]157). Juga penegasan bahwa Nabi Isa as wafat secara alami serta tidak adanya lagi kemungkinan Nabi Isa as turun kembali ke bumi sebagai al-Masîh. ${ }^{6}$ Teologi Ahmadiyah seperti ini selain memperlihatkan pendekatan penafsiran rasional Ahmadiyah terhadap al-Quran karena menganggap tidak rasional jika hingga saat ini Nabi Isa as masih hidup, juga mempertegas perbedaan Ahmadiyah dengan aliran dalam Islam yang menganggap Nabi Isa as nanti akan turun kembali ke bumi menjelang Kiamat untuk menumpas Dajjal.

\section{E. Messianisme Ahmadiyah}

Pengikut Ahmadiyah menyebut Mirza Ghulam Ahmad dengan al-Masîh Setelah wafat, Ghulam Ahmad diganti oleh penerusnya dan penerusnya digelar Khalifah al-Masîh (Pengganti al-Masih). Dan memang Yohanan Friedmann menyebut Ahmadiyah sebagai gerakan mesianik dalam Islam modern. Di dalam ahmadiyah.id, tampak bahwa Jemaat Ahmadiyah di Indonesia menyebut Mirza Ghulam Ahmad dengan Hadhrat, namun tetap menyebut penerusnya dengan Khalifah alMasîh dan tentu saja al-masîh yang dimaksud adalah Ghulam Ahmad sendiri.

Kata messia, messianisme, dan al-masîh $\underline{h}$ berasal dari bahasa Ibrani, meshiah yang berarti "diurapi" yang aslinya adalah perlambang seorang raja yang pemerin-

${ }^{6}$ Yohanan Friedmann, "Ahmadiyya", dalam Encyclopaedia of Qur'an Volume 1, Jane Dammen McAuliffe (ed.), hal. 51. 
tahannya dikuduskan dalam suatu upacara pengangkatan dengan minyak. ${ }^{7}$ Dengan demikian, istilah al-masîh sangat akrab dalam tradisi Yudeo-Kristiani. Karena itu, bisa dipahami jika Nabi Isa as disebut al-masîh dalam al-Quran.

Dalam Islam, istilah al-masîh lebih sering berkonotasi Nabi Isa as. ${ }^{8}$ Meski demikian, ada dua sosok lain yang sering disebut al-masîh yaitu al-Mahdi dan Dajjal. Yang disebut belakangan adalah al-masîh palsu. Latar belakang kedatangan al-masîh Mahdi adalah kondisi akhir zaman yang penuh kebobrokan moral sehingga harus datang seorang al-masîh yang dikirim oleh Allah swt untuk menghidupkan kembali Islam dan keimanan kepada Allah swt serta menebarkan keadilan dan kesejahteraan di seluruh dunia. kedatangan Mahdi memicu kedatangan al-Masîh

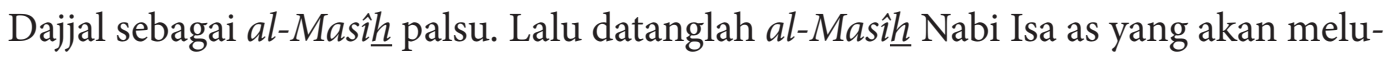
ruskan semuanya. Itulah yang mengawali peristiwa Kiamat. ${ }^{9}$

al-Masîh-nya Ghulam Ahmad mungkin tidak berkaitan dengan al-Masîh Nabi Isa as karena itu khas Nabi Isa as dan Nabi Isa as tidak akan pernah turun lagi akibat telah wafat secara alami. Itu menurut Ghulam Ahmad sendiri. Dan pasti tidak juga berkaitan dengan al-Masîh-nya Dajjal karena itu adalah al-Masîh palsu dan sesat. Kemungkinan besar al-Masîh-nya Ghulam Ahmad terkait dengan al-Masîh Mahdi karena Mahdi bukan nama orang tapi gelar untuk orang yang terpetunjuk, sedangkan Ghulam Ahmad mengklaim dirinya mendapatkan keistimewaan spiritual yang berbeda. Itu bisa diartikan sebagai terpetunjuk atau Mahdi. Selain kenyataan adanya keyakinan bahwa zaman telah mendekati akhir dan di mana-mana kebobrokan moral terjadi, serta al-Masîh Mahdi tidak datang untuk membawa syariat baru, namun melanjutkan syariat Nabi Muhammad saw. Sama dengan klaim kenabian pengikut Ghulam Ahmad bahwa Ghulam Ahmad tidak membawa syariat baru.

Karena Mahdi bukan nama orang, maka banyak orang yang digelar Mahdi sepanjang sejarah Islam. Gelar Mahdi pernah disematkan kepada empat khalifah awal Islam yaitu Abu Bakar, Umar bin Khattab, Utsman bin Affan, dan Ali bin Abi Thalib. Setelah mereka, ada Husain bin Ali bin Abi Thalib juga digelar Mahdi, ada Umar bin Abdul Aziz, dan sebagainya. Syiah pun punya Mahdinya sendiri. ${ }^{10}$ bahkan di dalam teologi Syiah, Mahdiisme sangat populer meski dengan makna berbeda dengan Mahdiisme Sunni dan juga Ahmadiyah.

${ }^{7}$ Helmer Ringgren, "Messianism: An Overview", dalam Encyclopedia of Religion, Lindsay Jones (ed.), (New York: Macmillan, 2005), hal. 5972.

${ }^{8}$ Ada enam ayat yang berbicara tentang Nabi Isa as sebagai al-Masîh: QS. Ali Imran[3] 45; QS. al-Nisa [4] 157, 171, 172; QS. al-Maidah [5] 17, 72, 75; QS. al-Tawbah [9] 30 dan 31).

${ }^{9}$ Kamran Scot Aghaie, "Messianism: Messianism in Muslim Tradition", dalam Encyclopedia of Religion, Lindsay Jones (ed.), (New York: Macmillan, 2005), hal. 5979.

${ }^{10}$ Kamran Scot Aghaie, "Messianism: Messianism in Muslim Tradition”, dalam Encyclopedia of Religion, Lindsay Jones (ed.), hal. 5981. 
Helmer Ringgren melihat adanya hubungan konsep Messianisme dengan munculnya kultus lokal sebuah tempat sebagai akibat dari tubrukan antara agama lokal dengan tradisi Kristen yang dianut oleh kaum penjajah. Kemunculan Ahmadiyah yang menganggap musuh besarnya adalah misionaris Kristen bisa dipahami lewat sudut pantang ini. Di Indonesia pun tercatat banyak klaim kenabian sebelum kemerdekaan yang menjadikan penjajah Belanda yang Kristen sebagai musuh yang harus dibasmi. Bedanya dengan Ahmadiyah adalah ancaman Kristen tidak dianggap ancaman militer, tetapi semata ideoligi. Sedangkan klaim kenabian sebelum kemerdekaan di Indonesia sekaligus militer dan ideologi. Bisa pula dipahami bahwa dengan tidak lagi terasosiasi antara kolonialisme dengan Kristianitas dan tidak begitu gencarnya lagi acaman keduanya secara bersamaan, maka peluang munculnya Messianisme-Mahdiisme model Ahmadiyah semakin tipis. Tapi model lain masih sangat mungkin muncul.

Di dalam sejarah Islam, tampaknya ada hubungan antara Messianisme, Mahdiisme, dan Tajdid. Pada Ahmadiyah, ketiga hal itu berkaitan erat. Mirza Ghulam Ahmad disebut al-masîh ; posisi al-masîh $\underline{h}$-nya lebih merujuk kepada al-Masîh Mahdi daripada al-Masîh yang lain; dan peran Ghulam Ahmad sebagai pembaru (mujaddid) juga sangat ditekankan oleh pengikutnya.

Meski tidak ada rujukan kuat dari al-Quran dan rujukan Haditsnya pun diperdebatkan, Mahdiisme tetap mewarnai sejarah Islam. bahkan tradisi Sunni dan Syiah pun melanggengkan Mahdiisme. Di kalangan Sunni, Mahdiisme lebih merupakan keyakinan tentang datangnya pembaru (mujaddid) terakhir yang dikirim langsung oleh Allah swt di akhir zaman untuk memulihkan Islam kepada kemurniannya. Lebih merupakan upaya kebangkitan kembali daripada memulai zaman yang baru sama sekali. ${ }^{11}$ Mahdiisme Ahmadiyah tampaknya dekat ke arah seperti ini.

Mahdiisme Syiah agak berbeda. Bukan sebagai penanda akhir zaman dan bukan pula upaya kebangkitan kembali Islam, tetapi sejak semula lahir akibat ketertindasan dan ketidakberdayaan Syiah di hadapan supremasi Sunni. Karena Mahdiisme Sunni lebih cenderung merupakan ramalan dan Mahdiisme Syiah sudah terjadi sejak dahulu, maka Syiah lebih memiliki kesediaan menerima gagasan Mahdiisme daripada Sunni, dalam ukuran tertentu. ${ }^{12}$ Dalam hal ini, Mahdiisme Ahmadiyah agak berbeda namun kata kunci "keterdesakan" mempunyai kesamaan. Jika Syiah terdesak oleh Sunni hingga melahirkan Mahdiisme, maka Ahmadiyah terdesak oleh missionaris Kristen.

${ }^{11}$ Azyumardi Azra, "Mahdiisme: Doktrin dan Perkembangan Historis", dalam Rekonstruksi dan Renungan Religius Islam, Muhamad Wahyuni Nafis (ed.), (Jakarta: Paramadina, 1996), hal. 5981.

${ }^{12}$ Azyumardi Azra, "Mahdiisme: Doktrin dan Perkembangan Historis", dalam Rekonstruksi dan Renungan Religius Islam, Muhamad Wahyuni Nafis (ed.), hal. 5981. 


\section{F. Ahmadiyah dan Kenabian}

Kontroversi terbesar Ahmadiyah adalah pengakuan bahwa Mirza Ghulam Ahmad adalah seorang nabi. Inilah alasan utama untuk mengeksklusi Ahmadiyah dari Islam. Gencarnya kontroversi melahirkan Ahmadiyah faksi Lahori yang menganggap Ghulam Ahmad hanyalah mujaddid, bukan nabi. Boleh disebut bahwa Ahmadiyah faksi Lahori termasuk yang menutup pintu kenabian setelah Nabi Muhammad saw.

Masih terbuka dan sudah tertutupnya pintu kenabian setelah $\mathrm{Nabi} \mathrm{Mu}-$ hammad saw sesungguhnya adalah perdebatan lama yang muncul kembali dalam bentuk baru dan tidak persis sama. Perdebatan lama tentang kenabian adalah pertanyaan bagaimana seorang nabi bisa muncul? Apakah itu melalui proses manusiawi, semacam upaya manusia meningkatkan derajatnya hingga mampu mencerap wilayah Ilahiyah atau proses yang secara keseluruhan ditentukan semata oleh kehendak Allah swt? Apakah semua orang bisa menjadi nabi? Apa perbedaan nabi dengan wali?

Ketika ada pengakuan kepada Ghulam Ahmad sebagai nabi, maka itu membuktikan kekhawatiran lama ortodoksi Islam terhadap pemikiran para filosof yang berimplikasi pada kehadiran nabi-nabi baru dari kalangan manusia biasa. Dalam bukunya, Kontrovesi Kenabian dalam Islam: Antara Filsafat dan Ortodoksi, Fazlur Rahman menegaskan bahwa kekhawatiran ortodoksi Islam tidak beralasan karena dengan segala kemampuannya, para filosof sendiri secara tegas menyangkal bahwa setiap pemikir atau mistikus mana pun tidak mungkin bisa menjadi nabi. ${ }^{13}$ Bahkan bari para filosof, untuk menjadi nabi, tidak bisa sekadar manusia biasa. Jangankan menjadi nabi, menjadi filosof saja tidak bisa manusia biasa.

Kekhawatiran ortodoksi Islam berdasar pada pemikiran para filosof tentang potensi akal. Salah satunya adalah al-Farabi yang menyatakan bahwa kemampuan akal manusia dibagi dalam tiga tingkatan: (1) akal potensial: kemampuan melepaskan/mengatakan arti-arti/bentuk-bentuk material; (2) akal aktual: kemampuan menangkap arti lepas dari materi; dan (3) akal mustafad: kemampuan menangkap makna dalam bentuk murni yang berada di luar alam manusia. Hubungan manusia dengan alam spiritual, yang disebut Akal Aktif, menggunakan daya akal mustafad ini. ${ }^{14}$ Diandaikan jika seorang manusia mencapai akal mustafad dan mampu memahami hakikat-hakikat, maka sudah mirip

${ }^{13}$ Fazlur Rahman, Kontroversi Kenabian dalam Islam: Antara Filsafat dan Ortodoksi, (Bandung: Mizan, 1996), hal. 116.

${ }^{14}$ Fazlur Rahman, Kontroversi Kenabian dalam Islam: Antara Filsafat dan Ortodoksi, hal. 36. 
dengan nabi. Dan jika semua orang mungkin mencapai akal mustafad itu, maka semua orang pun mungkin menjadi nabi. Inilah kekhawatiran itu. Dengan cara berfikir para filosof dimungkinkan tidak akan lahir nabi yang membawa syariat baru, namun masih mungkin lahir nabi dalam ukuran intelektual karena kemampuan akal itu tadi. Pandangan seperti ini mirip dengan pendapat al-Hakim al-Tirmidzi, sebagaimana dikutip oleh Ikhlas Budiman, bahwa kenabian adalah mengabarkan hakikat-hakikat ilahiyyah dan makrifat-makrifat rabbaniyyah dalam bentuk esensi, sifat, nama, dan perbuatan. Karena itu, kenabian menjadi terbagi dua yaitu nubuwwah al-ta'rîf (kenabian untuk memperkenalkan) dan nubuwwah al-tasyrî' (kenabian untuk membawa syariat). ${ }^{15}$ Kenabian model kedua memang bisa ditutup dengan pemikiran para filosoaf, tetapi kenabian model pertama itulah yang dikhawatirkan oleh ortodoksi Islam.

Filosof menolak kemungkinan semua orang bisa menjadi nabi lewat alasan bahwa untuk menjadi seorang nabi dibutuhkan kapasitas akal yang tidak biasa. Akal yang tidak biasa itu disebut Akal Kenabian. Karena tidak semua orang dianugerahi Akal Kenabian, maka tidak semua orang bisa menjadi nabi. Adapun ortodoksi Islam menolak kemungkinan semua orang bisa menjadi nabi lewat cara menegaskan wewenang Ilahi langsung daripada membuka penjelasan mengenai kemampuan-kemampuan alamiah jiwa manusia.

Graham E. Fuller mengajukan persolan yang menarik. Persoalannya seperti ini, dalam memandang agama Abraham yang lain seperti Kristen dan Yahudi, umat Islam dengan mudah mengklaim Islam sebagai agama paling sempurna karena ibarat edisi, Islam adalah edisi terbaru dari rangkaian ajaran agama Abraham. Karena merupakan edisi terbaru, maka Islam pastilah lebih lengkap dan lebih universal. Yang menjadi masalah adalah pandangan umat Islam ini hanya sampai pada Islam. Lalu bagaimana dengan ajaran atau yang datang setelah Islam? Bukankah itu bahkan merupakan edisi yang lebih baru dari Islam? Dan jika analogi keterbaruan bisa dipakai sebagai alasan Islam sebagai pengganti agama sebelumnya, bisakah analogi serupa dipakai terhadap Islam oleh ajaran yang datang setelahnya? ${ }^{16}$

Kenyataannya, memang banyak klaim kenabian setelah Nabi Muhammad saw, bahkan di awal-awal Islam. Di Indonesia, Ahmadiyah adalah ajaran kenabian impor dari India-Pakistan, padahal Indonesia juga banyak melahirkan nabi-nabi dalam negeri dan paling belakangan dan populer adalah Lia Eden dan

\footnotetext{
${ }^{15}$ Ikhlas Budiman, Pengalaman Religius dalam Tafsir Sufi: Perpektif Genealogis, (Jakarta: Disertasi belum terbit di Program Pascasasarjana Institut PTIQ Jakarta, 2016), hal. 99.

${ }^{16}$ Graham E. Fuller, Apa Jadinya Dunia Tanpa Islam?: Sebuah Narasi Sejarah Alternatif, (Bandung: Mizan, 2014), hal. 50.
} 
Ahmad Mushaddiq. ${ }^{17}$ Di era sebelum kemerdekaan, klaim kenabian berkaitan dengan kolonialisme. Ini sejalan dengan pemikiran Helmer Ringgren. Namun setelah kemerdekaan, klaim kenabian lebih berkaitan dengan kemerosotan moral atau menurut Al Makin adalah penguatan identitas diri bangsa yang sedang mengalami masa transisi.

\section{G. Kesimpulan}

Secara sosio-teologis, selalu ada kemungkinan lahir nabi dan klaim kenabian seperti halnya Ahmadiyah di manapun dan kapanpun. Intervensi negara mungkin berhasil menekan gerakan itu agar tidak berani muncul ke permukaan dan memilih untuk begerak di bawah tanah, tetapi tidak akan efektif menghilangkannya. Setiap krisis yang terjadi adalah tempat dan tanggal lahir klaim-klaim seperti itu. Uniknya, agama-agama yang kini telah mapan, bahkan Islam, adalah agama-agama yang dulunya muncul pada momentum-mementum krisis juga. Dalam Islam, sangat sering disebutkan bahwa Islam datang untuk menghapus kejahiliahan dan membawa manusia dari alam kegelapan menuju alam terang benderang. Yang menjadi pertannyaan selanjutnya bagi setiap klaim kenabian adalah apakah klaim itu cukup kuat untuk menghimpun pengikut atau tidak. Jika tidak, maka klaim kenabian itu akan hilang dari panggung sejarah, tergerus oleh ortodoksi agama-agama yang sudah mapan atau tergerus oleh klaim-klaim kenabian yang datang lebih belakangan.

${ }^{17}$ Bahasan tentang nabi-nabi di Nusantara ada dalam Al Makin, Nabi-Nabi Nusantara: Kisah Lia Eden dan Lainnya, (Yogyakarta: Suka Press, 2017). 


\section{Daftar Pustaka}

Aghaie, Kamran Scot, "Messianism: Messianism in Muslim Tradition”, dalam Encyclopedia of Religion, Lindsay Jones (ed.), (New York: Macmillan, 2005)

Al Makin, Nabi-Nabi Nusantara: Kisah Lia Eden dan Lainnya, (Yogyakarta: Suka Press, 2017)

Azra, Azyumardi, "Mahdiisme: Doktrin dan Perkembangan Historis", dalam Rekonstruksi dan Renungan Religius Islam, Muhamad Wahyuni Nafis (ed.), (Jakarta: Paramadina, 1996)

Budiman, Ikhlas, Pengalaman Religius dalam Tafsir Sufi: Perpektif Genealogis, (Jakarta: Disertasi belum terbit di Program Pascasasarjana Institut PTIQ Jakarta, 2016)

Esposito, John L., Islam Warna-Warni: Ragam Ekspresi Menuju "Jalan Lurus", (Jakarta: Paramadina, 2004)

Friedmann, Yohanan, "Ahmadiyah", dalam Ensiklopedi-Oxford Dunia Islam Modern Jilid 1, John L. Esposito (ed.), (Bandung: Mizan, 2002)

"Ahmadiyya", dalam Encyclopaedia of Qur'an Volume 1, Jane Dammen McAuliffe (ed.), (Leiden: Brill, 2001)

Fuller, Graham E., Apa Jadinya Dunia Tanpa Islam?: Sebuah Narasi Sejarah Alternatif, (Bandung: Mizan, 2014)

Rahardjo, M. Dawam, "Mitos dalam Agama dan Kebudayaan”, dalam Rekonstruksi dan Renungan Religius Islam, Muhamad Wahyuni Nafis (ed.), (Jakarta: Paramadina, 1996)

Rahman, Fazlur, Kontroversi Kenabian dalam Islam: Antara Filsafat dan Ortodoksi, (Bandung: Mizan, 1996)

Ringgren, Helmer, "Messianism: An Overview", dalam Encyclopedia of Religion, Lindsay Jones (ed.), (New York: Macmillan, 2005) 
86 Mumtäz Vol. 1 No. 1, Tahun 2017 